\title{
Treatment of Cataract in Diabetics with and without Retinopathy
}

\author{
HUNG CHENG and SUZETTE L. FRANKLIN \\ Oxford
}

\begin{abstract}
Summary
The results of cataract surgery in diabetic patients was reviewed. The visual outcome was good in the absence of retinopathy and was not significantly different from that of non-diabetic patients. Eyes with retinopathy achieved significantly worse visual results and the prognosis was related to the severity of retinopathy. Clinical cystoid macular oedema occurred significantly more frequently in eyes with retinopathy than without and there were significantly more eyes with retinopathy which became blind or partially sighted.

The use of a Projectoscope for assessing the amount of degradation of an image was tested. A good correlation was found between the amount of blurring of the test target and the drop in visual acuity.
\end{abstract}

The optimal type of cataract surgery is discussed and lines of management outlined.

The association of cataract and diabetes mellitus (DM) is well known ${ }^{1}$ and there is a significant correlation between prevalence of cataract and age as well as duration of diabetes. $^{2}$ These factors are also determinants of the severity of retinopathy ${ }^{3}$ and therefore one can expect cataract to occur in patients with diabetic retinopathy.

The treatment for disabling cataract is surgical and current trends would couple lens extraction with intraocular lens (IOL) implantation. Approximate estimates of the prevalence of lens implantation in cataract surgery is about 80 to $90 \%{ }^{4}$ which is probably true for both the United Kingdom and the United States. There is no longer any absolute contraindication to lens implantation and it is, therefore, surprising to read in the "consultation" section of the American Intraocular Implant Society Journal $^{5}$ that all members of the advice panel listed diabetic retinopathy of one form or other as a contraindication.

The purpose of this paper is to examine the problems of cataract surgery related to the presence of diabetic retinopathy and suggest possible ways of surmounting them.

\section{Review of literature}

The presence of diabetes mellitus (DM) per se appears not to be an adverse factor for obtaining good results with IOL surgery. Both Clayman ${ }^{6}$ and Straatsma ${ }^{7}$ claimed high success rates in the absence of retinopathy. Sebestyn ${ }^{8}$ claimed to have comparable results but he included cases of early retinopathy and his percentage of eyes with good acuity was substantially below those of Clayman and Straatsma. In a series which included cases with maculopathy and pre-proliferative changes Ngui et $\mathrm{al}^{9}$ reported similar findings. When present, diabetic retinopathy significantly reduces good visual outcome. Before the use of IOLs became widespread Caird et al $^{1}$ reported poor visual results after cataract surgery when retinopathy was established; and, Aiello et $\mathrm{al}^{10}$ also reported significantly greater incidences of vitreous 
haemorrhage and neovascular glaucoma after intracapsular extraction, for both active and "non-active" proliferative disease.

In a randomised controlled trial involving small numbers, Alpar ${ }^{11}$ showed that intracapsular extraction (ICCE) had significantly more complications following surgery compared to extracapsular extraction (ECCE) but his numbers were too small to be meaningful when he tried to compare different styles of IOLs.

In reviewing 25 patients, Thompson et al ${ }^{12}$ claimed that it was possible to document and treat diabetic retinopathy even in the presence of iris-supported lenses but the duration of follow-up of their patients was very variable. Sebestyn ${ }^{8}$ made similar claims for the posterior chamber lens that "examination, photography, and photocoagulation treatment of the retina were not affected by the presence of an intraocular lens". However, he had excluded patients with more than mild retinopathy so that, apart from Ngui's ${ }^{9}$ no report so far has dealt with the management of eyes with cataract in which diabetic retinopathy is the predominant disease.

\section{Review of personal experience}

In view of the dearth of information, we have reviewed our personal experience. The notes of patients admitted under one of us (HC) with the secondary diagnosis of diabetes mellitus recorded on the "Oxford Record Linkage Study" computer, were examined if cataract surgery was performed between 1982 and 1986. Only eyes with a minimum follow-up of six months were included.

\section{Eyes without retinopathy}

There were 28 eyes in 21 patients with DM and no retinopathy. All had ECCE and posterior chamber lens implants with the exception of four eyes, of which two had anterior chamber lenses and two had iris supported lenses. The mean age was 73 and only one patient was less than 60 years of age. One eye had vitreous loss and three eyes developed clinical cystoid macular oedema which was confirmed by fluorescein angiography. Two eyes developed background retinopathy and three patients, contributing five eyes, had age-related macular degeneration (ARMD).

Eighty-eight per cent of eyes had visual acuity of $6 / 12$ or better within the first anniversary of surgery (Fig. 1) and this result is comparable to other published results, $, 6,7$ thus, being not significantly different from those obtained in non-diabetic patients. ${ }^{13}$ Of the three eyes with visual acuity less than 6/ 12, two belonged to patients with ARMD and one had an iris prolapse and resultant vitritis.

\section{Diabetics with retinopathy}

There were 18 eyes from 15 patients with retinopathy and the fate of these eyes is shown in Table I.

Six of the 18 eyes did not have IOLs and were operated on at the beginning of the review period. The visual acuity of the eyes are plotted in Figure 2. Eyes with proliferative retinopathy are represented by a different symbol from eyes with background retinopathy but maculopathy was only denoted if the diagnosis was known beforehand.

In eight of the 18 eyes (seven of the 15 patients) clinical cystoid macular oedema (CMO) was recorded. Diagnosis was based on the rapid deterioration from one week to the next by two lines or more of Snellen acuity, or the subsequent recovery of vision by two lines or more of acuity without laser photocoagulation in the first six months after surgery. Only in one case was there some doubt that the diagnosis of CMO could have been wrongly made and that it might have been diabetic maculopathy in an eye already affected by proliferative retinopathy. There were only three out of 28 eyes ( 21 patients) in the group without retinopathy and the difference between the two groups, with and without retinopathy, is statistically significant (Table II; $\mathrm{p}=\mathbf{0 . 0 2}$ ).

Only one out of five eyes with proliferative retinopathy gained improvement in VA of two lines or more of Snellen acuity. In contrast, six eyes with background retinopathy improved by two lines or more and five eyes improved by four lines or more. Comparing the retinopathy group with the group without retinopathy in terms of visual 
improvement, the difference is statistically significant $\mathrm{p}<0.01$, Table II.

Proportionately more eyes with proliferative retinopathy became blind $(\mathrm{VA}<6 / 60)$ or partially sighted $(\mathrm{VA}=6 / 60)$. In the group as a whole there were six eyes reaching this stage, and compared to the group of DM without retinopathy, the difference was statistically significant (p. $<0.01$, Table II).

\section{Discussion of results}

Our results suggest that cataract surgery in diabetics is not significantly different from that of non-diabetics in the absence of retinopathy. In the course of one year, very few eyes deteriorated and only two out of 28 eyes developed retinopathy.

The visual results in the presence of diabetic retinopathy are significantly worse, especially when proliferative retinopathy is

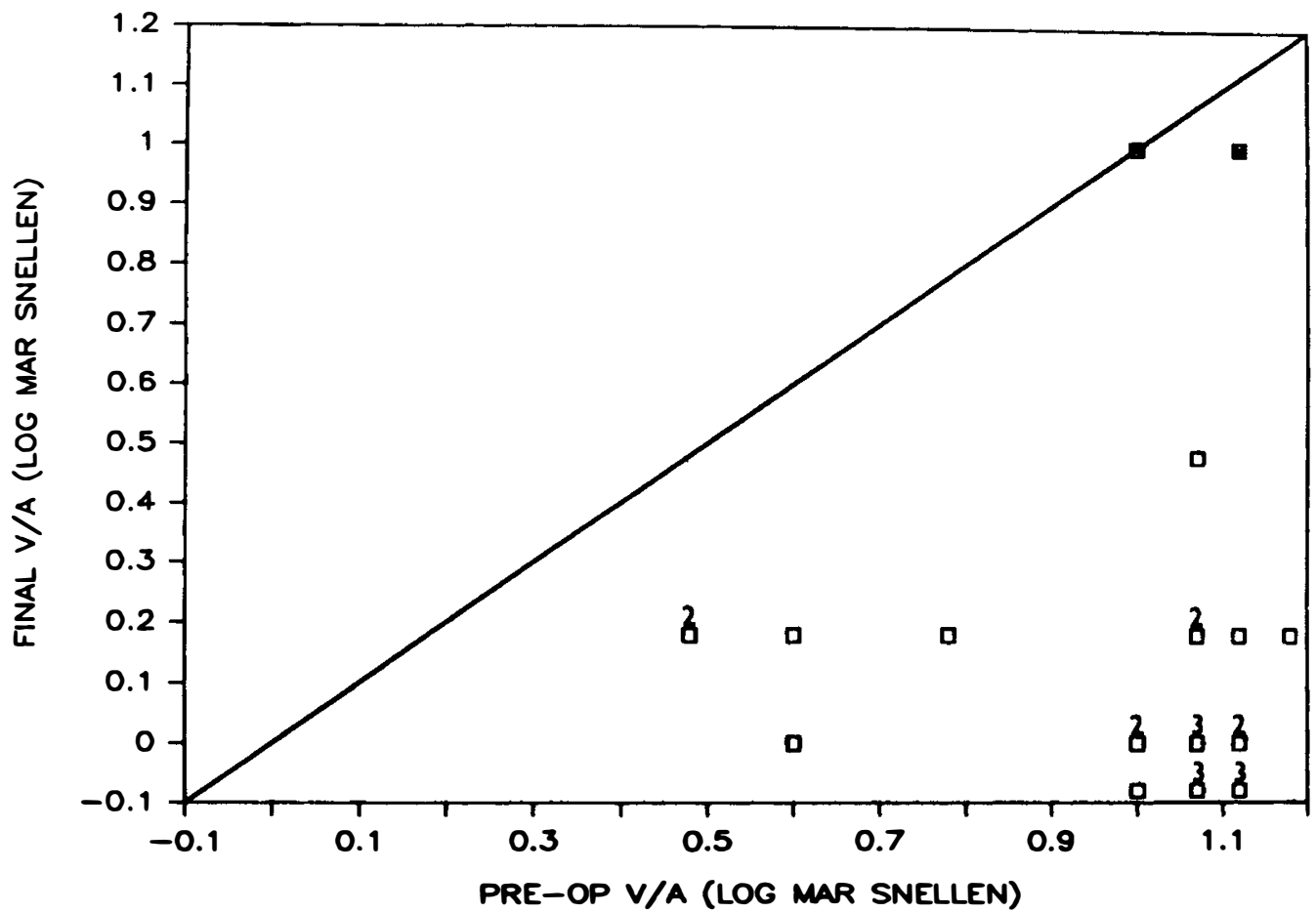

Fig. 1. Diabetics + cataract extraction with no retinopathy. Pre-operative visual acuity vs final postoperative visual acuity ( $\log M A R$ Snellen) - indicates those with ARMD (age-related macular degeneration).

Table I Fate of eyes with diabetic retinopathy after cataract surgery

\begin{tabular}{|c|c|c|c|c|c|c|c|c|c|c|}
\hline \multirow[b]{2}{*}{$\begin{array}{l}\text { Retinopathy } \\
\text { type }\end{array}$} & \multicolumn{7}{|c|}{ Number of eyes in each category } & \multirow[b]{2}{*}{$\begin{array}{c}\text { Blind or } \\
\text { partially } \\
\text { sighted }\end{array}$} & \multirow{2}{*}{\multicolumn{2}{|c|}{$\begin{array}{l}\text { No. of lines } \\
\text { Snellen gainea }\end{array}$}} \\
\hline & $\begin{array}{l}\text { Total } \\
\text { no. of } \\
\text { eyes }\end{array}$ & $\begin{array}{l}\text { With } \\
\text { IOL }\end{array}$ & $\begin{array}{l}\text { BG to } \\
\text { Prolif }\end{array}$ & $P / C$ & $\begin{array}{l}\text { Rube- } \\
\text { osis }\end{array}$ & $\begin{array}{c}\text { Vit } \\
\text { haem }\end{array}$ & $C M O$ & & & \\
\hline $\begin{array}{l}\text { Proliferative } \\
\text { (Prolif) }\end{array}$ & 5 & 4 & & 5 & & & & 3 & 1 & \\
\hline Background (BG) & 13 & 13 & 2 & 8 & 1 & 2 & 8 & 3 & 1 & 5 \\
\hline
\end{tabular}

$\mathrm{P} / \mathrm{C}=$ Photocoagulation treatment applied

$\mathrm{CMO}=$ Cystoid Macular Oedema

Vit Haem = Vitreous Haemorrhage 
present. Photocoagulation was required in the majority of these cases but in spite of treatment, the visual outcome was poor in a large proportion of cases.

It would appear that the chief determinant of visual outcome is the severity of retinopathy and that cataract surgery per se is necessarily incomplete and must form part of a continuing treatment.
Therefore, some important considerations in management can be formulated:

(1) Timing of intervention - including knowing ways of predicting the likelihood of visual improvement following surgery;

(2) Choice of treatment -

(a) to facilitate observation and treatment of retinopathy;

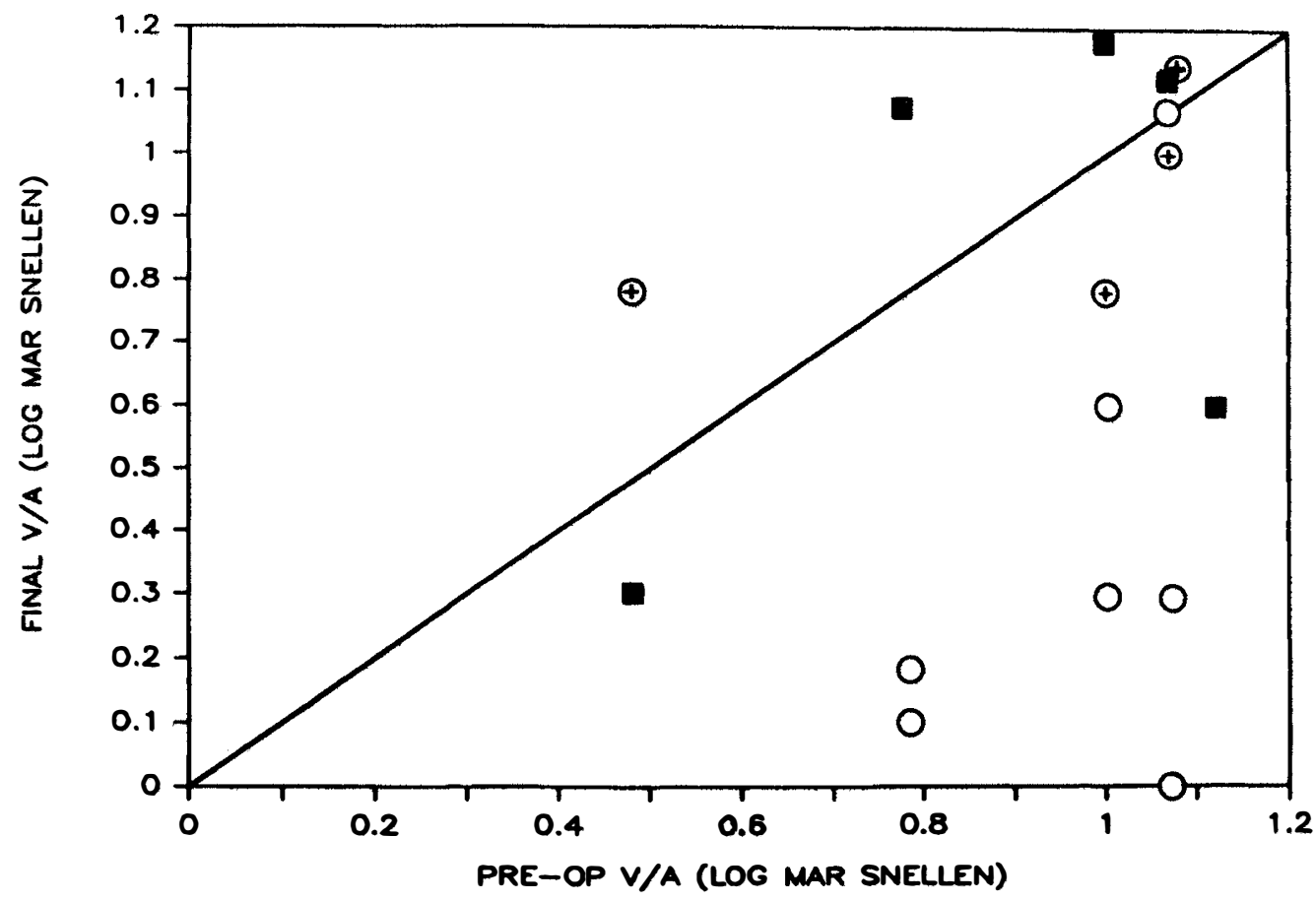

Fig. 2. Diabetics + cataract extraction with retinopathy.

- = proliferative retinopathy; $\bigcirc=$ background retinopathy; $\Theta=$ maculopathy.

Table II Outcome of cataract surgery in diabetes mellitus comparison of eyes with and without retinopathy

\begin{tabular}{|c|c|c|c|c|c|c|c|}
\hline & \multicolumn{2}{|c|}{$C M O$} & \multicolumn{2}{|c|}{$\begin{array}{l}\text { Blind or partially } \\
\text { sighted }\end{array}$} & \multicolumn{2}{|c|}{$\begin{array}{l}\text { Improvement in } \\
\text { Snellen } V A\end{array}$} & \multirow[t]{2}{*}{$\begin{array}{l}\text { Total in } \\
\text { each }\end{array}$} \\
\hline & $+v e$ & - ve & $+\mathrm{ve}$ & $-v e$ & $\geqslant 2$ & $<2$ & \\
\hline With retinopathy & $8^{*}$ & 10 & $6^{\neq}$ & 12 & $7^{* *}$ & 11 & 18 \\
\hline Without retinopathy & 3 & 25 & $0(3)$ & $23(2)$ & 23 & 5 & 28 \\
\hline Total & 11 & 35 & 9 & 37 & 30 & 16 & 46 \\
\hline
\end{tabular}

Figures in ( ) = number of eyes thus affected by ARMD

Results $x^{2}$ test: ${ }^{*}=\mathrm{p}=0.02$

$$
\begin{aligned}
& \neq=p=0.01 \text { (if ARMD is excluded) } \\
& * *=p<0.01
\end{aligned}
$$


(b) to minimise surgical complication;

(3) Need for continuing management of retinopathy.

\section{Timing of intervention}

Since the chief determinant of good vision is the severity of retinopathy, it is important to differentiate the contributions of cataract and retinopathy to the fall in vision at any particular stage. Where the cataract precludes visualisation of retinal details, cataract surgery is not controversial and is likely to improve vision even if central vision is not ameliorated. It is also desirable for the proper monitoring of retinopathy. However, where cataract and retinopathy both exist in moderate amount, it is difficult to discern the relative contribution of each, especially where maculopathy is present. Some objective measure is needed beside visual acuity.

By quantifying the degradation of an image projected through the cataract on to the retina one means of assessing objectively the contribution of the cataract is already available. This device has been described by Cotlier ${ }^{14}$ and consists of mounting a reduced image of a 3 bar USAF resolution target in an ophthalmoscopic device which projects the image on to the retina (Fig. 3). An observer counts the number of groups of bars which still remain visible as separate bars, thus giving an index of transparency of the media. Using such a device on 56 eyes with only cataract and no retinal pathology we have found a good correlation between Snellen visual acuity and the number of countable bars, thus confirming the claims of Cotlier et al. ${ }^{14}$ The correlation coefficient in our study was $-0.81 \quad\left(\mathrm{p}<10^{-6}\right)$ suggesting that this device is useful clinically to help judge the optimum time for cataract surgery (Fig. 4).

In a separate study involving 30 eyes of diabetics with cataract but only mild or no retinopathy, a good correlation was still obtained but there was a shift to the right of the regression line suggesting a tendency to over-estimation of the true acuity in this group of patients (correlation coefficient $=-0.69$ Fig. 4 ).

Unfortunately, a complementary test of assessing true acuity is not available. The use of a visometer or laser interferometer does not give a reliable guide ${ }^{15}$ and tends to overestimate the true visual acuity in our experience (unpublished results).

\section{Choice of treatment}

The form of surgery should leave an adequate aperture for observation and this would preclude the use of iris-clip lenses.

Bearing in mind the tendency of eyes with retinopathy to vitreous haemorrhage, rubeotic glaucoma ${ }^{10}$ and $\mathrm{CMO}$, the type of

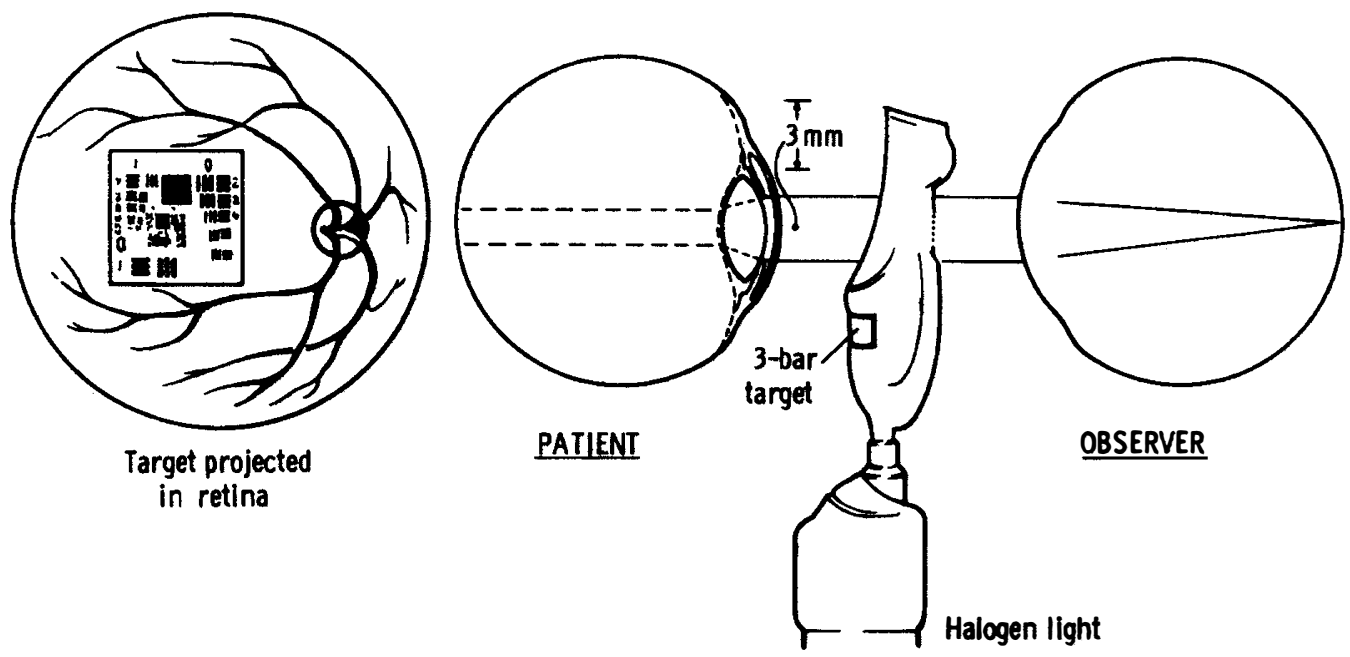

Fig. 3. The use of a Projectascope to throw a USAF resolution target on to the retina (after Cotlier 1982). 
surgery chosen should have a low predisposition to these complications. ECCE would seem preferable as the intact capsule may have a barrier effect to diffusion forward of any vasogenesis factor ${ }^{16}$ or backwards of a putative agent inducive of $\mathrm{CMO},{ }^{17}$ and it may have a physical effect by not allowing herniation of vitreous through to the anterior chamber. Since the presence of an IOL will not affect light transmission significantly and photocoagulation through an IOL is not a problem $^{8,9}$, the use of a posterior chamber lens after ECCE is not contra-indicated. Indeed, it may be an advantage in that, after capsulotomy, the presence of an IOL will continue to provide a physical barrier to stop vitreous herniation.

Thought needs to be given to the capsule as thickening and after cataract will occur in a significant percentage. ${ }^{18}$ In case of capsule opacification the size of the aperture will depend on pupil diameter. The determining factor must be the ability to see up to the equator by means of direct ophthalmoscopy. New vessels seldom arise beyond the equator but may not be visible by indirect ophthalmoscopy because of low magnification. Therefore, an aperture large enough to permit fundoscopy up to the equator would be adequate and if more peripheral ablation is needed it can always be achieved by cryo-therapy. ${ }^{19}$

It is even possible to make theoretical calculations of the required gap in the capsule for visualisation of the equator. If one assumed average dimensions for the globe ${ }^{20}$ one can calculate the principal points of a theoretical eye and to back trace a ray from the equator on a scale drawing. Knowing the dimensions of the pseudophakos and its refractive index as well as the AC depth one can estimate the size of the gap needed for this purpose for a given pupil size. Using Gullstrand's Schematic Eye No 2 and an anterior chamber depth of $3.6 \mathrm{~mm}$ (mean measurements from a random

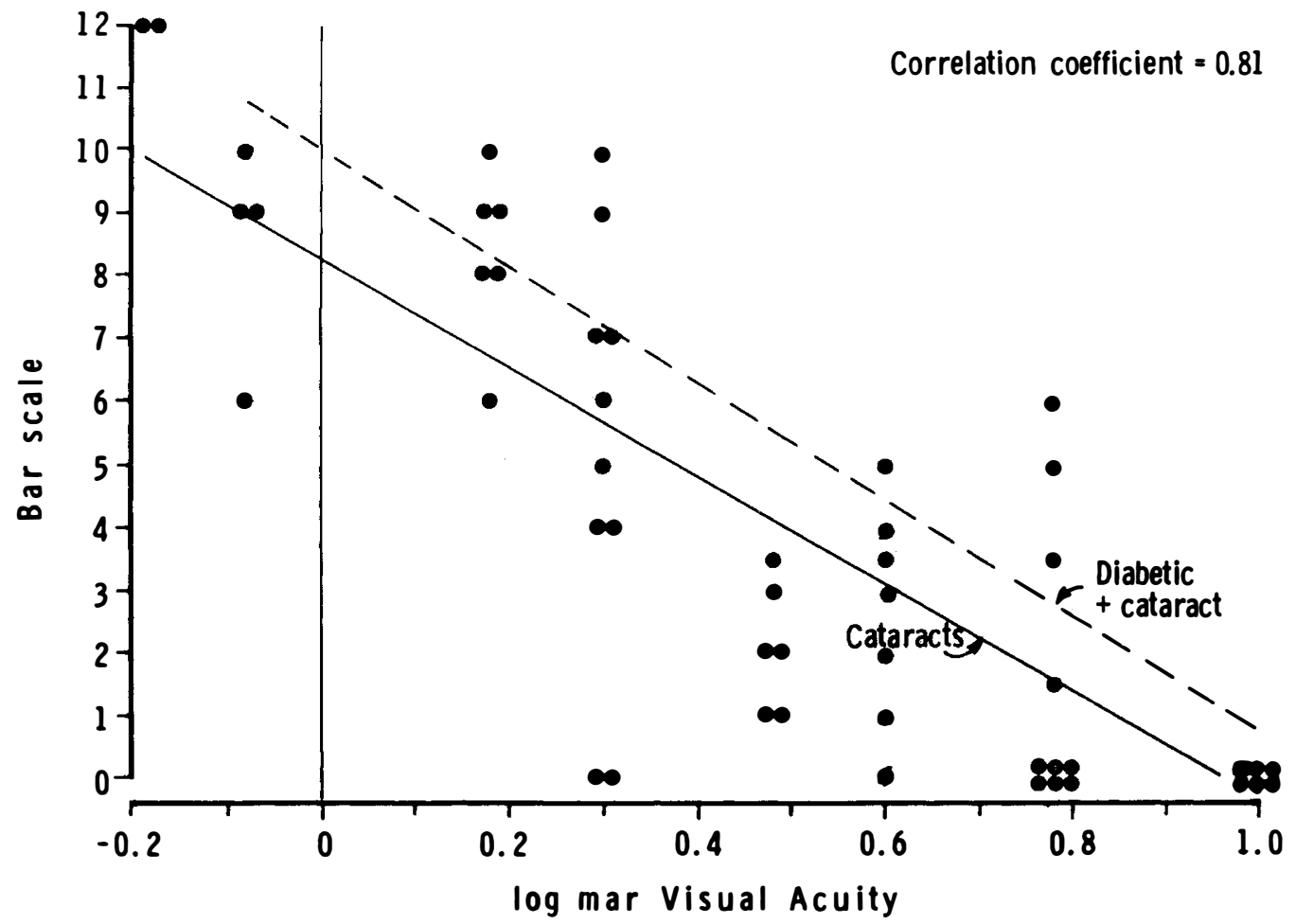

Fig. 4. Graph of Visual Acuity vs USAF 3 BAR TARGET SCALE seen with Projectascope in cataract patients. 
sample) taken from the posterior surface of the cornea to the anterior surface of the implant, one can deduce that an eye with a pupil size of $8 \mathrm{~mm}$ will need an aperture of $5 \mathrm{~mm}$ in the capsule for visualisation of a point at the equator through the middle mirror of the Goldman 3 mirror gonioscope (Fig. 5). ${ }^{21}$ Clearly, a number of assumptions are being made but such a theoretical model allows one to make approximate estimates in quantitative terms.

Bearing this in mind, where capsule opacification is increasing, there is a case for early capsulotomy in order to take advantage of the elastic nature of the capsule. If the YAG-laser was used for the capsulotomy it may be judicious to obtain the required opening in stages in order to avoid using too many applications in one sitting which may produce prolonged ocular hypertension or glaucoma.

The diagnosis of CMO could not be proved in all our cases as the one test which is pathognomonic (ie, petaloid macular fluorescence) is not always applicable in the presence of retinopathy. However, the clinical behaviour of a dramatic fall of vision and the spontaneous recovery in a few cases would support our impression. Bearing this in mind there is a strong case for using indomethacin either topically ${ }^{22}$ or orally ${ }^{23}$ as prophylaxis.

Other measures include the use of capsular fixation of the IOL to minimise uveal irritation $^{24}$ and of topical or depo-steroids post-operatively to minimise iritis which has a known association with $\mathrm{CMO} .^{25}$

\section{Continuing management}

Close supervision of eyes with retinopathy is essential and if photocoagulation is required, arrangements should be made before the patient is discharged from hospital in order not to miss the opportunity for intervention at the optimal time. In the case of proliferative retinopathy, additional sutures may facilitate treatment eg, two to three weeks after cataract surgery.

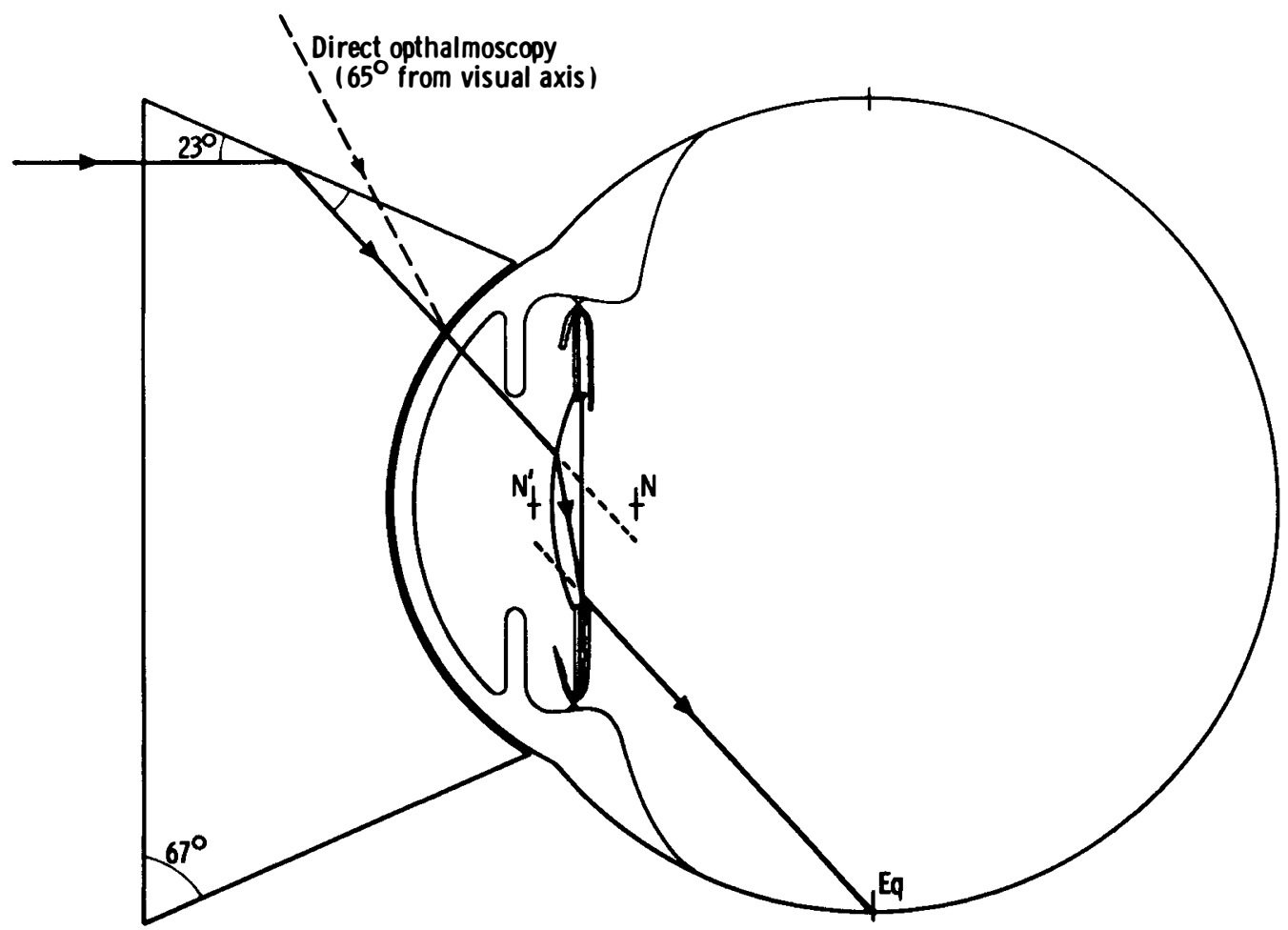

Fig. 5. Pseudophakic eye - limiting ray path for view of equator. 
If posterior capsule opacification should reduce visualisation and interfere with photocoagulation, one should not hesitate to use cryo-coagulation, especially if only the peripheral retina is inaccessible. ${ }^{19}$

While diabetics without retinopathy do not have an immediate problem, the development of retinopathy is a function of duration of DM and degree of glycaemic control. Therefore, in some cases, the treatment of cataract in DM should be delivered with this possibility in mind and allowances made for the need for continuing observation.

\section{Footnote}

This paper was based on a lecture delivered to the Ophthalmic Section of the Royal Society of Medicine, December 1985.

We thank Mrs Linda Wood and Mr. N. C. Price for helping with computation of data, Mr. J. M. Sparrow and Dr N. P. Brown for the loan of the Projectoscope and Dr A. Hill for the scale drawings of a theoretical eye. We are indebted to Miss Ivy Samuel for secretarial help and Donald Barbour for photography.

\section{References}

${ }^{1}$ Caird FI, Pirie A, Ramsell TG: Diabetes and the Eye. Blackwells. Oxford 1969; p8-10, p127-139.

${ }^{2}$ Klein BEK, Klein R, Moss S: Prevalence of cataracts in a population-based study of persons with diabetes mellitus. Ophthalmol 1985; 92: 1191-6.

${ }^{3}$ Klein R, Klein BEK, Moss SE et al. The Wisconsin Epidemiologic Study of Diabetic Retinopathy II and III. Arch Ophthalmol 1984; 102: 520-32.

${ }^{4}$ Jaffe NS: The outlook for intraocular lenses through 1990. J Cat Refract Surg 1986; 12: 267-73.

${ }^{5}$ Consultation Section. Ed DD Shephard. Am Intraocular Implant Soc J 1985; 11: 504-7.

${ }^{6}$ Clayman HM, Jaffe NS, Light DS: Lens implantation and diabetes mellitus. $A m J$ Ophthalmol 1979; 88: 990-2.

${ }^{7}$ Straatsma BR, Pettit TH, Wheeler $\mathrm{N}$ et al. Diabetes mellitus and intraocular lens implantation. Ophthalmol 1983; 90: 336-43.

${ }^{8}$ Sebestyn JG: Intraocular lenses and diabetes mellitus. Am J Ophthalmol 1986; 101: 425-8.

${ }^{9}$ Ngui MSH, Lim ASM, Chong AB: Posterior chamber intraocular lenses in diabetics. Internat Ophthalmol 1985; 8: 257-9.

${ }^{10}$ Aiello LM, Wand M, Liang G: Neovascular glaucoma and vitreous haemorrhage following cataract surgery in patients with diabetes mellitus. Ophthalmol 1983; 90: 814-20.

${ }^{11}$ Alpar JJ: Cataract extraction and diabetic retinopathy. Am Intraoc Implant Soc J 1984; 10: 433-7.

12 Thompson SM, Kritzinger EE, Roper-Hall MJ: Should diabetes be a contra-indication for an intraocular lens? Trans Ophthalmol Soc UK 1983; 103: 115-7.

${ }^{13}$ Straatsma BR, Meyer KT, Bastek JV et al. Posterior chamber intraocular lens implantation by ophthalmology residents. A prospective study of cataract surgery. Ophthalmol 1983; 90: 327-35.

${ }^{14}$ Cotlier E, Fagadau W, Chicchetti DV: Methods for evaluation of medical therapy of senile and diabetic cataracts. Trans OSUK 1982; 102: 416-22.

${ }^{15}$ Halliday BL and Ross JE: Comparison of two interferometers for predicting visual acuity in patients with cataract. Brit $J$ Ophthalmol 1983; 67: 273-7.

${ }^{16}$ Glazer BM, D'Amore PA, Lutty GA et al. Chemical mediators of intraocular neovascularisation. Trans OSUK 1980; 100: 369-71.

17 Ozaki L. The barrier function of the posterior capsule. Am Intraoc Implant Soc J 1984; 10: $182-4$.

${ }^{18}$ Binkhorst CD: Five hundred planned extracapsular extractions with irido-capsular and iris-clip lens implantation in senile cataract. Ophthalmic Surg 1977; 8: 37-44.

19 Vernon S and Cheng H: Panretinal cryotherapy in neovascular disease. $\mathrm{Br} \mathrm{J}$ Opht almol. (In press.)

${ }^{20}$ Duke-Elder S: The anatomy of the visual system. Henry Kimpton. London 1961. System of Ophthalmology. Vol II, p80.

${ }^{21}$ Hill A: Personal communication, 1985.

${ }^{22}$ Miyake K, Sakamura S, Miura H: Long-term follow-up study on prevention of aphakic cystoid macular oedema by topical indomethacin. Br J Ophthalmol 1980; 64: 324-8.

${ }^{23}$ Klein RM, Katzin HM, Yannuzzi LA: The effect of indomethacin pre-treatment of aphakic cystoid macular oedema. Am J Ophthalmol 1979; 87: 487-9.

${ }^{24}$ Champion R, McDonnell PJ, Green WR: Intraocular lenses. Histopathologic characteristics of a large series of autopsy eyes. Surv Ophthalmol 1985; 30: 1-32.

${ }^{25}$ Laatikainen L: Cystoid macular edema: clinical course and characteristics. Surgical Pharmacology of the Eye. Ed M Sears and A Tarkkanen. Raven Press. New York 1985: p551-564. 